\author{
Francisco Tomsich
}

\title{
Desfase en dirección única. Notas sobre los orígenes del videoarte en Uruguay y Eslovenia
}

\author{
Palabras clave: videoarte, Uruguay, Eslovenia, conceptualismo, dictadura, cultura \\ alternativa
}

DOI: $10.4312 /$ ars.11.2.351-364

\section{Introducción}

Existe en la actualidad un creciente interés en establecer correspondencias y comparaciones entre Europa del Este y América del Sur en el campo de las artes visuales, especialmente durante el período comprendido entre 1960 y 1989, aproximadamente. Hay tres factores que contribuyen a justificarlo. El primero de ellos es el vínculo directo entre ambas regiones, en parte creado por las diferentes olas de migraciones en ambas direcciones y sus procesos históricos, y en parte por el intercambio cultural vinculado o no a ellas. El segundo es la constatación y análisis de una serie de puntos en común en el campo de la creación artística a partir de la década de $1960^{1}$. El tercer factor es la «contemporaneidad» (Preda, 2015, 56) de «regímenes dictatoriales» en diversos países de ambas regiones en las décadas de 1970 y 1980, un contexto en el que «estrategias para lidiar con todo tipo de medidas políticas de represión fueron cultivadas simultáneamente» (Dressler, 2010)².

Hay una serie de problemas, empero, que hacen que este corpus de referencias, aunque insoslayable, requiera ser matizado a la hora de hablar del caso yugoslavo en lo que respecta al tercer factor de la lista, dadas las peculiares características políticas, económicas y sociales del mismo en el concierto de los países de Europa del Este, al punto que no es raro leer, como en De Baere y en un contexto de comparaciones similares a las que nos ocupan, la serie «Eastern Bloc, Yugoslavia and South America» (De Baere, 2012, 2). Los trabajos de Caterina Preda en este campo de análisis comparativo, por ejemplo, suelen dejar de lado Yugoslavia y Checoslovaquia debido

1 Es el tema de las muestras Art under Conditions of Political Repression: 60s-80s / South America / Europe (Württembergischer Kunstverein Stuttgart, 2010), Transmissions: Art in Eastern Europe and Latin America, 1960-1980 (MoMA, Nueva York, 2015-2016) y Témpano. El problema de lo institucional. Cruces entre Europa del Este y el Río de la Plata (Museo de Arte Contemporáneo de Montevideo/Museo Nacional de Artes Visuales, Montevideo, 2017).

2 Un cuarto factor es la necesidad de reconstruir los puentes perdidos que conectaban proyectos macropolíticos emancipatorios y producción artística en ambas regiones. 
a la relativa apertura y tolerancia de los gobiernos socialistas de estos dos países hacia las prácticas artísticas críticas y la porosidad de los programas y las políticas oficiales para las artes ${ }^{3}$.

Este texto se ocupará de la cuestión de los orígenes del videoarte en Uruguay y Eslovenia (países que tienen, a pesar de sus enormes diferencias, ciertas similitudes ${ }^{4}$ ) como un ejemplo de las dificultades de estas comparaciones, por otra parte siempre estimulantes, y también de las que presenta ese otro lugar común que supone a los países de América del Sur en general y a los del Este de Europa en general operando en «márgenes» similares de los centros hegemónicos de producción (e historización) artística.

\section{«Los orígenes del videoarte» como problema}

El término videoarte se utiliza comúnmente en la actualidad para referirse a cualquier tipo de producción audiovisual hecha por artistas, lo cual incluye una gran variedad de tecnologías, modos de producción y modalidades de exhibición. Esta aceptación, sin embargo, oculta una historia de terminologías encontradas, que muchas veces reflejan y/o determinan antagonismos entre grupos e individuos, gestos de diferencia que manifiestan posiciones políticas, estéticas y metodológicas diversas y afectan al mismo tiempo la historiografía:

Hacia el final de la década central del siglo XX surgió en Estados Unidos y Europa una compleja y desconcertante forma de arte. Se la llamó videoarte, video de artistas, video experimental, televisión de artistas, «la nueva televisión»... incluso «Guerrilla TV». (Meigh-Andrews, 2014, 2)

En un texto de 1976, David Ross afirma:

La idea de desmaterializar el arte, que unió a un grupo muy variado de escultores, bailarines, poetas, pintores y documentalistas en eclécticas investigaciones multimedia sobre la naturaleza del arte, parece haber cristalizado en una serie de actividades llamadas (de una manera bastante ineficaz) videoarte (Sichel, 2006, 25).

La cuestión de los orígenes es un tema central de esta complejidad, ya que muchas de las obras que pasan por pioneras del videoarte no utilizaban la tecnología seriada para consumo de masas que se asocia al «origen» de 1965, el año en que Sony lanza

3 Ver: Preda, 2013, 12.

4 Entre ellas, el número de habitantes y su «medianía» entre grandes o poderosos vecinos, que probablemente contribuye a configurar algunos rasgos del carácter nacional. También un alto grado de centralización cultural en sus respectivas capitales y un alto nivel de alfabetización y acceso a la educación terciaria (al menos durante el siglo XX). 
al mercado el primer equipo portátil de video (Portapak), mientras que esta última fecha señala, a su vez, el momento en que la accesibilidad (relativa) de los medios de producción que hacen posible el videoarte, con su fundamental percepción de sí mismo como antagonista de la televisión, se convierte en un tópico ${ }^{5}$. Para Graciela Taquini «el videoarte no se puede definir a través de la idea de soporte, de cinta, de cassette, sino que comienza con el uso consciente del hardware». (Taquini, 2008, 28), mientras que Barbara Borčič, estudiando la historia del medio en Yugoslavia, se refiere al videoarte exclusivamente cuando se utiliza cinta magnética (Borčič, 2003, 491). Éste último es el criterio que aplico aquí, ya que me interesa comparar dos narrativas de la historia del medio centradas en los primeros usos de esa tecnología específica en Uruguay y Eslovenia.

Tanto la cuestión de los orígenes como los problemas vinculados a la «dependencia tecnológica» (Meigh-Andrews, 2014, 6), la agónica relación con la televisión y las cuestiones del archivo y la institucionalización, son comunes a todos los contextos en los que surgen las prácticas que asociamos al término videoarte. Esta universalidad también está presente en la cuestión de las formas, contenidos y funciones. De hecho, las tres «áreas» o «sub-géneros» (ibíd.) inaugurados por la «vanguardia del video» en Estados Unidos que analiza el filme documental Vídeo: The New Wave, de 1973, serán replicados por los artistas pioneros del medio en todo el mundo, contemporánea o tardíamente, y ofician de marcos en los que esas nociones y usos de formas, contenidos y funciones se activan. Este compendio ${ }^{6}$, escrito y narrado por Brian O'Doherty, presenta tres grandes modelos de actuación de los artistas del videoarte. Uno de ellos es la experimentación con la tecnología misma y sus especificidades, que suele llevar a obras centradas en el ritmo y el color, tildadas muchas veces de «abstractas», pero también a la apropiación, subversión y manipulación de imágenes preexistentes. Otro es el uso del video que toma partido por la inmediatez y accesibilidad del medio para producir documentación, registro y «televisión alternativa», que tiende a enfatizar las posibilidades del medio para aliarse con, y contribuir a, procesos de (contra-) información, democratización y emancipación. El tercero se caracteriza por hacer del video una herramienta en el taller del artista, que lo utiliza para registrar, exhibir y elaborar procesos; se asocia al cuerpo como material, a la performance, a la tradición del (auto)retrato. Esta útil categorización también habla de nociones de públicos, estrategias de exhibición y tradiciones de imágenes en las que estos pioneros operan. Es a través de las prácticas de los artistas vinculados al tercer modelo de actuación

5 Artistas que experimentaban con tecnología de video en el campo artístico antes de esta fecha podían hacerlo gracias a que trabajaban en compañías o instituciones que contaban con esos recursos, mientras que el desarrollo de la tecnología específica estaba estrechamente ligada a la industria bélica norteamericana.

6 Video: The New Wave, 1973, 58:27 minutos, blanco y negro/color, sonido. Producido por WGBH y dirigido por Fred Barzyk. 
que el videoarte se convierte en un medio privilegiado del Arte Conceptual y de los conceptualismos en general, por ejemplo, mientras que muchos de los artistas que trabajaban en la manipulación electrónica del medio estaban estrechamente relacionados con la composición musical y la danza.

\section{La aparición del videoarte en Eslovenia y Uruguay}

Existen grandes diferencias entre Uruguay y Eslovenia en lo que respecta a la literatura, los archivos y los proyectos de investigación que se ocupan del videoarte y su historia. Si bien los otros países del Cono Sur ${ }^{7}$ cuentan con importantes antecedentes en proyectos de investigación y archivo, Uruguay adolece de escasez de iniciativas similares, mientras que la primera exhibición acompañada de catálogo crítico que se ocupó exhaustiva y específicamente de la historia del videoarte uruguayo se realizó en el año $2007^{8}$, si bien tuvo un precursor en un «Laboratorio» realizado el año anterior ${ }^{9}$. En cuanto a Eslovenia, ya en 1999 existe al menos una importante publicación de análisis histórico-crítico (Videodokument. Video Art in Slovenia 19691998) acompañada por exhibiciones en el marco institucional de lo que a partir del año 2000 se llamará SCCA ${ }^{10}$, sede actual de un completo y activo archivo de videoarte esloveno y yugoslavo, DIVA, disponible también, en su mayor parte, para visionado en línea. Este desequilibrio entre los panoramas de Eslovenia y Uruguay en este terreno también puede percibirse en el campo pedagógico y académico, así como en la atención que crítica e historiografía del arte le dedicaron desde sus comienzos al videoarte, mientras que la producción experimental de video en el marco de la TV pública era en Eslovenia (incluso antes de 1969, fecha del primer videoarte esloveno, ver: Zajc, 1999) una posibilidad a la que ningún artista uruguayo podía aspirar en el período dictatorial (1973-1985).

Por otra parte, es posible arriesgar la hipótesis de que el videoarte fue, en Uruguay, más rápidamente institucionalizado que en Eslovenia. Ya en agosto de 1988 -solo cinco años después de lo que se considera el primer videoarte uruguayo- se realizó en el

7 La denominación «Cono Sur» refiere tradicionalmente a los territorios de Argentina, Chile y Uruguay, que comparten una serie de coordenadas históricas, sociales y económicas.

8 La condición video. 25 años de videoarte en el Uruguay. Centro Cultural de España, Montevideo, 2007. El texto central producido por Enrique Aguerre, curador de esta muestra, es, con variantes, el mismo que conforma la sección dedicada a Uruguay en Vídeo en Latinoamérica. Una historia crítica (AECID, 2008, una de las pocas antologías de textos sobre videoarte con una perspectiva continental), por lo que puede considerarse, a estas alturas, un relato hegemónico.

9 05982:01 (Julio de 2006) fue organizado por la Fundación Arte Contemporáneo de Montevideo, con la curaduría de Ángela López Ruiz. Incluyó un ciclo de charlas, muestras y actividades públicas vinculadas a un archivo en proceso. No existen hasta el momento archivos exhaustivos de videoarte uruguayo accesibles al público general.

10 Ver: http://www.scca-ljubljana.si/ [15. 10. 2017]. 
Museo Nacional de Artes Visuales (MNAV, Montevideo) la muestra Videoarte en el Uruguay, jalonando un proceso de conexión entre un núcleo de artistas locales y la principal institución museal del país, que incluyó la producción y exhibición de obras a lo largo de muchos años gracias al apoyo de su entonces director, Ángel Kalenberg. Uno de estos artistas pioneros del videoarte en Uruguay, Enrique Aguerre, es hoy director del MNAV, y otro de ellos, también integrante del Núcleo Uruguayo de Video Arte $^{11}$, Fernando Álvarez Cozzi, trabaja en la misma institución en el Departamento de Video. A pesar de ello, el crítico Nelson Di Maggio escribía en 2001 que «estos artistas se formaron en ausencia de maestros y con dificultades de exhibición» (Peluffo Linari, 2014, 55). Este tema ciertamente controvertido es importante porque señala, también, hacia el campo minado, y por ende aún poco estudiado, de las historias políticas del arte bajo dictadura ${ }^{12}$ y sus persistencias hoy. Estas consideraciones también apuntan a la cuestión de la construcción de un canon centrado en lo visible a nivel institucional, en el uso de determinadas tecnologías y en una acotación territorial, que necesariamente deja fuera del relato histórico amplios sectores de la producción (contextos geográficos periféricos, cultura subterránea, producción funcional a otras manifestaciones artísticas, obras realizadas por mujeres y por artistas uruguayos exiliados en el extranjero, cine experimental, etc.).

La mayor evidencia del gran desfase entre los contextos uruguayo y esloveno es, empero, la datación de las primeras obras de videoarte (en tanto uso de cinta magnética) realizadas por artistas locales (con equipamiento, claro está, producido en el extranjero). "La historia del video arte en Eslovenia comienza con Belo mleko belih prsi [Blanca leche de blancos pechos], realizado en 1969 por Nuša y Srečo Dragan. Eslovenia estuvo entonces presente en los mismos comienzos de este tipo de creación en el mundo». (Dragan, 2014a, 32). En Uruguay, mientras tanto, la primera pieza de videoarte, Voy por el camino (del Grupo Teatro y Danza de Montevideo ${ }^{13}$ ) fue producida recién en 1982. Es curioso constatar que, de los tres modelos de actuación de los pioneros del videoarte

11 NUVA, fundado en setiembre de 1988 por Eduardo Acosta Bentos, Enrique Aguerre, Fernando Álvarez Cozzi, José Claudio, Julia Gadé, Roberto Mascaró, Clemente Padín y María Cristina Seoane.

12 Uno de los casos que ilustran este punto, y que viene a cuento en el contexto de esta investigación, es el del envío uruguayo a la sección latinoamericana, curada por Ángel Kalenberg, de la X Bienal de París (1980), que incluyó a Álvarez Cozzi (como dibujante) y que produjo gran rechazo en una parte de la comunidad de artistas latinoamericanos, que consideraban que Kalenberg representaba los intereses del régimen militar uruguayo. El intento de boicot a dicha Bienal, iniciado por Felipe Ehrenberg en México, parece haber sido determinante en la decisión del gobierno de facto uruguayo de detener y encarcelar al artista Clemente Padín, también partícipe y co-organizador de la protesta. Es interesante comprobar que Álvarez Cozzi y Clemente Padín fundarían en 1988 el NUVA (ver nota al pie 11) y participarán juntos en numerosas muestras de videoarte uruguayo a partir de 1985. Ver: «Expediente: Bienal X. La historia documentada de un complot frustrado», del Grupo Proceso Pentágono (Documentos | Redes Intelectuales en América Latina, Item \#90, http://redesintelectuales. net/documentos/items/show/90 [15. 10. 2017]).

13 Integrado por Fernando Álvarez Cozzi, Julia Gadé y José Claudio. El grupo, fundado en 1974, produjo entre 1975 y 1980 tres cortometrajes en $16 \mathrm{~mm}$. 
mencionados ut supra, es el segundo (diversos tipos de anti-televisión y de registro documental vinculado al activismo político) el que menos exponentes presenta durante el período fundacional del videoarte, tanto en Eslovenia como en Uruguay. Los otros dos modelos, centrados en la experimentación con las especificidades del medio en sí mismo o en su uso como herramienta de registro y comunicación de procesos, fueron dominantes. En ese sentido, la pieza inaugural de la historia del videoarte uruguayo es bastante atípica, especialmente en el contexto general de la producción de su principal responsable en tanto video, Fernando Álvarez Cozzi, aunque sintomática. Voy por el camino (1982, 16 minutos) es, esencialmente, el registro de una coreografía (de Julia Gadé) para dos «actores-bailarines» de danza contemporánea (Julia Gadé y José Claudio) en diversos escenarios urbanos. Mas allá de la edición, realizada mediante «inserts en la propia cámara» (Aguerre, 2007, 17), esta pieza de danza filmada no presenta características formales o contenidos que exploten las especificidades del medio video. La música, por otra parte, está presente en todo momento (en off) y consiste en una serie de musicalizaciones creadas por Maorik Techeira sobre textos en verso escritos por niños de una zona rural del interior de Uruguay en la década de 1930. Esta banda sonora es, desde el punto de vista estilístico, tradicional y folclórica; desde el punto de vista formal está sujeta a una estructura de serie de canciones independientes con secciones instrumentales y recitados; desde el punto de vista de los contenidos es naíf y vagamente lírico-optimista-vitalista («las manos aprietan la flor de la vida/ y en su cavidad se guardan la luz para ver las estrellas»; "voy por el camino / voy hasta donde él me lleve / voy hasta donde se pierda / bajando la voz»). Este aspecto restringe grandemente el posible interés de las acciones de los bailarines (es un ejercicio interesante observar el video sin sonido) y, sumado a las estrategias de presentación de la obra (pantallas de título y créditos que recuerdan modelos cinematográficos) y al recurso utilizado para darle «final» (seguimiento de las acciones de los bailarines en un parque, cámara en mano / encuadre central de los mismos detenidos en una composición de cuerpos rectos, sin contacto, en figuras mixtas de tendencia abierta, una de las cuales señala hacia arriba / elevación de la cámara / encuadre de las copas de los árboles/ fundido a negro), le otorgan al conjunto una muy extraña combinación de ingenuidad y auto-complacencia. La evidente ausencia de ironía, por otra parte, no justifica una lectura de tipo alegorizante de mensajes o intenciones de cualquier tipo que los artistas hayan intentado transmitir de forma soterrada dadas las condiciones de censura y autocensura imperantes en el medio local.

Tras la realización de Voy por el Camino, de todos modos, Álvarez Cozzi, «decepcionado por la [baja] calidad de la imagen y por la tosquedad del equipamiento video- comienza a experimentar con la técnica semicontrolada del feedback» (Aguerre, 2007, 18), dando comienzo así a un largo período de experimentación con el material 
video y su relación con el sonido (Variaciones en espiral, 1983; Anticlips, 1985, con música de Meredith Monk), cuyos resultados son mucho más sofisticados, a la vez que pueden asociarse mucho más fácilmente con trabajos similares realizados por pioneros en los centros artísticos globales, si bien Álvarez Cozzi afirma (Álvarez Cozzi, 2007, 13) que no sabía que otros artistas estaban trabajando con el mismo recurso. Otros representantes clave de esta etapa inicial del videoarte en Uruguay también empiezan a producir, a partir de 1984, otros tipos de obras, especialmente interesantes cuando establecen relaciones con el campo de la poesía experimental y la performance (Roberto Mascaró, Verónica Artagaveytia, Clemente Padín, Eduardo Acosta Bentos). Los dos últimos produjeron trabajos con un contenido latente o explícito muy alto de crítica y denuncia a las prácticas de tortura y desaparición de enemigos del régimen llevadas a cabo por la dictadura, como en el caso de Por el arte y por la paz (Clemente Padín, 1984). Este último modelo de actuación, vinculado a la representación de la violencia institucional en el propio cuerpo, no tiene parangón en la producción eslovena de videoarte, en al que la crítica explícita del régimen está centrada en la manipulación paródica de símbolos, discursos e imágenes del poder. Al contrario, la importancia de la sexualidad, la pornografía y el erotismo en el videoarte esloveno desde sus inicios no tiene correlato en Uruguay (más allá de casos aislados), mientras que la relación de los videoartistas con la música rock y punk, que en Eslovenia tuvo una importancia superlativa en el proceso de (auto)representación de la «escena alternativa» de los 80 , es en Uruguay un aspecto lateral, o al menos así parece en vistas de la bibliografía sobre el tema producida hasta ahora (y esta perspectiva debe revisarse).

En Eslovenia, una línea de trabajo característico del primer modelo de actuación, que también incluyó trabajos interdisciplinarios y colaboraciones con grupos de danza contemporánea, es la de Miha Vipotnik en los años 70, mientras que Nuša y Srečo Dragan, creadores de las primeras obras de videoarte en Eslovenia, provenían del campo del conceptualismo, que «daba prioridad al aspecto comunicacional, inmaterial y no figurativo» y utilizaba con frecuencia «videogramas conceptuales ascéticos» (Kovič, 1999, 35). Para esta pareja de artistas, según otro autor,

[...] el arte es un lenguaje alternativo, una forma de comunicación, cuya manifestación exterior es el proceso creativo. Este proceso es completamente no-material y se realiza solo en el medio de la idea: lo que muestran las cintas de video, las fotografías o los filmes que producen es, en su opinión, solo un impulso para la mente del espectador. (Brejc, 1978, 19)

Mientras tanto, Barbara Borčič agrega que: «Para ellos, el video constituía un elemento de la acción artística y al mismo tiempo era usado como herramienta de documentación. Era entendido esencialmente como un medio de comunicación interactiva inmediata con la audiencia.» (Borčič, 1999, 11). 
La primera pieza de videoarte producida en Eslovenia, Blanca leche de blancos pechos (1969, reconstruida en $1994^{14}$ ), justifica absolutamente estas observaciones. Se trata de una «imagen estática que se proyecta en la pantalla mientras una discusión se lleva a cabo entre los participantes de la acción: la imagen cambia en la percepción de los participantes en tanto ellos mismos participan en la acción filmada» (Kovič, 1999, 31), La imagen estática proviene de un film (Beli ljudi, de Naško Križnar, 1970) y muestra el pecho desnudo de una mujer, sobre cuyo pezón una jeringuilla vierte una gota de leche. Los cambios en la imagen están dados por la superposición de signos gráficos tales como diagramas que refieren a los participantes en la "comunicación grupal simultánea» (Dragan, 2014b, 3) y sus diferentes roles en el proceso semiótico, y textos que describen el proceso mismo, mientras que el sonido está conformado por un collage de voces en diversas lenguas que emiten sentencias sobre el videoarte mismo («la musique de chambre de notre époque»; «video art starts tomorrow...»). «El video concluye con un diagrama del 'resultado' del video, el diálogo en sí mismo.» (Dragan, 2014b, 3) ${ }^{15}$.

La filiación de este trabajo con el cine experimental contemporáneo de Jean-Luc Godard, la teoría semiótica y estructuralista y el Arte Conceptual es evidente, y su (quizá masturbatorio) aggiornamiento contrasta fuertemente con la escasez de referencias comparables a las que podían acceder los artistas uruguayos que comenzaron a trabajar en videoarte más de una década después. A modo de ilustración de esto valga el caso del propio Álvarez Cozzi, que además de integrar el Grupo Teatro Danza de Montevideo forma parte, a partir de 1978-1979, del colectivo de artistas Octaedro ${ }^{16}$, uno de los principales responsables de una renovación de la escena artística (en plena dictadura) a través de la apropiación de estrategias y métodos del Arte Conceptual. Es interesante comprobar, gracias al estudio sobre el caso realizado por la investigadora uruguaya May Puchet, la importancia que tanto Álvarez Cozzi como algunos de sus compañeros de grupo le otorgan a una copia de Idea como Arte. Documentos sobre el Arte Conceptual, de Gregory Battcock, que circuló entre ellos y que significó una influencia determinante en un momento en que «Uruguay estaba bastante aislado de lo que pasaba en el mundo» (Puchet, 2014, 92). Es importante constatar, de paso, que también Nuša y Srečo Dragan son en Eslovenia parte de un grupo de artistas, $\mathrm{OHO}$, que también opera, en el contexto esloveno, la definitiva apropiación del conceptualismo, y es en el contexto de esa asociación de artistas que surgen los primeros experimentos en video de la pareja. En Uruguay, las «relecturas del Arte Conceptual» realizadas

14 Los avatares de la existencia material de este trabajo lo convierten en un típico caso de obra pionera atravesada por diversos y a veces contradictorios relatos sobre, por ejemplo, su duración original y la tecnología utilizada para realizarla.

15 Es menester agregar que Voy por el camino fue estrenada en una sala de cine en 1983, mientras que la obra de los Dragan se exhibió en un circuito de galerías y centros culturales alternativos.

16 Integrado por Carlos Barea, Fernando Álvarez Cozzi, Gabriel Galli, Juan Carlos Iglesias, Miguel Lussheimer, Carlos Rodríguez, Abel Rezzano y Carlos Aramburu. 
durante la dictadura tuvieron un perfil diferente, en parte porque estaban signadas por un contexto de censura y autocensura mucho más pronunciado y en parte debido al proverbial conservadurismo de la escena artística uruguaya, contra el que estos artistas se rebelaban sin dejar, por otra parte, de ejemplificar en ocasiones. Así, la «inmaterialidad» perseguida por los artistas de $\mathrm{OHO}$ era muy resistida en los trabajos de Octaedro, Los Otros o Axioma, por ejemplo, y el video, por otra parte, no fue una herramienta privilegiada en el trabajo de los grupos que representaron en Uruguay en dictadura una «línea conceptualista» clara.

\section{El videoarte en la «apertura»}

Es curioso constatar que ambos contextos sociopolíticos, el esloveno y el uruguayo, suelen ser analizados en términos de «apertura» en la época en que surgen las prácticas artísticas que hemos analizado:

La política yugoslava de apertura a otros países en la década de 1960 generó una serie de muestras internacionales [...] Los jóvenes artistas yugoslavos conocían las ideas revolucionarias de los años 60 y 70 en Occidente, y se identificaban con el arte conceptual, corriente en ese tiempo, en un aspecto sobre todo: el de confrontar las instituciones artísticas conservadoras que sostenían la jerarquía académica del mundo del arte y sus formas de expresión clásicas. En tanto cuestionaban todo, descubrían canales diferentes y más independientes. (Borčič, 2003, 493)

La identificación con el arte conceptual (o al menos la necesidad de comprenderlo y asimilarlo), la confrontación con las instituciones artísticas conservadoras y la búsqueda de canales alternativos fueron características de los artistas y grupos de artistas que comenzaron a trabajar durante el período dictatorial en Uruguay, a comienzos de la década de 1980, mientras que la «apertura» que comenzó a avizorarse con claridad hacia 1983 se dirigía no solo hacia otros países, sino al final de la dictadura, que para la mayoría era (y no había demasiadas opciones reales) sinónimo de regreso del sistema democrático-parlamentario pluripartidista «de antes». En todo caso, la disolución de Yugoslavia dejó a los países que la integraban en una posición similar, en muchos aspectos, a la que accedieron los países del Cono Sur al finalizar los períodos dictatoriales, y casi contemporáneamente. Esa dirección única de ambos procesos «de apertura» llevó al neoliberalismo económico, la inserción en el mercado global y la homogeneización del sistema político siguiendo el modelo de las democracias occidentales hegemónicas, y, tanto en América del Sur como en el Este de Europa, significó la derrota política y social de todo proyecto alternativo al que propugna la gran narrativa teleológica global del capitalismo. 
Las cuestiones de la «apertura hacia qué» y la (auto)crítica del papel que los intelectuales y artistas cumplieron en el proceso de «transición», relativamente común en el medio cultural de los países de la ex-Yugoslavia, no tiene parangón en Uruguay, donde sería difícil de imaginar una «autocrítica radical» como la que realiza Bogdan Lešnik en su análisis del rol del video y los artistas de video en la «cultura alternativa» de Liubliana en los años 80 , «que se pensaba a sí misma como una especie de revolución minimalista» pero que, en cambio, era «no una revolución, sino el fin de la revolución, su disolución». En este raro ensayo, que parte del fracaso (ejemplificado en un proyecto frustrado de TV alternativa) de las expectativas puestas en el videoarte como «objeto» y como «herramienta de documentación» de la cultura alternativa eslovena, Lešnik llega a decir que «en tanto de algún modo dependía del sistema que subvirtió, no es sorprendente que, en efecto, [la cultura alternativa] no solo contribuyera a eliminar el antiguo sistema, sino que también contribuyó a la eliminación de sí misma en tanto posición política relevante que, durante un tiempo, de hecho fue.»Y aún más:

Hoy es bastante posible afirmar que la escena alternativa en este país fue meramente la forma concreta de una «contra-revolución» que estaba ocurriendo [...] a mucho mayor escala y que ciertamente determinó esa escena. Y si llevamos esta idea hasta sus últimas consecuencias: la escena [alternativa] vino a ocurrir precisamente con el fin de ejecutar [esa contrarevolución] (o al menos hacer la transición más suave). (Lešnik, 1999, 52)

Este texto extraordinario, airado, sincero y sin duda exagerado (en sentido filosófico ${ }^{17}$ ) nos lleva de nuevo a la cuestión inicial sobre los estudios que consideran «comparables» los «regímenes dictatoriales» de Yugoslavia y de los países del Cono Sur, en tanto lo impensable de una manifestación semejante en el contexto uruguayo no habla tanto de que no sea posible, sino de que no sería verosímil: ningún integrante de los grupos e individuos que podríamos asociar a la "cultura alternativa» de Uruguay en dictadura se consideraría a sí mismo cumpliendo un papel reaccionario a través de ninguna de las prácticas, gestos, conductas y acciones consideradas entonces como pruebas de «apertura» cultural. Esta puesta en diálogo un tanto desasosegante y oscura señala, en mi opinión, hacia la conformación de un vacío en la atención puesta en Uruguay a los procesos internos que, en las historias del arte, comunican el período pre-dictatorial, la dictadura y la pos-dictadura, lo cual ha llevado a una clara despolitización de la historia, la teoría y la praxis del arte, a una escasez preocupante de crítica institucional y a una aceptación del mejor de los mundos posibles tras una catástrofe cultural que se considera terminada, pero sigue operando en el presente en numerosos campos y a diferentes niveles. La práctica del videoarte, por las condiciones

17 Ver: García-Düttmann, A., Philosophy of Exaggeration (Continuum, 2007). 
de su surgimiento, su dependencia del desarrollo tecnológico, sus frecuentes vínculos con otras artes y sus modelos de actuación casi tipológicos, resulta un objeto de estudio muy apropiado para percibir y analizar este estado de cosas.

\section{Bibliografía}

Aguerre, E., La condición video, en: La condición video. 25 años de videoarte en el Uruguay, Catálogo de la exposición, Montevideo 2007, pp. 15-30.

Álvarez Cozzi, F., Videos de garage, en: La condición video. 25 años de videoarte en el Uruguay, Catálogo de la exposición, Montevideo 2007, pp.10-14.

Borčič, B., Video Art from Conceptualism to Postmodernism, en: Impossible Histories: historical avant-gardes, neo-avant-gardes and post-avant-gardes in Yugoslavia, 1918-1991 (eds. Djurić, D., Šuvaković, M.), Cambridge, MA 2003, pp. 490-520.

Borčič, B., Introduction, en: VIDEODOKUMENT. Video art in Slovenia 1969-1998, (ed. Borčič, B.), Ljubljana, 1999, pp. 9-19.

Brejc, T., Nuša and Srečo Dragan, en: The New Art Practice in Yugoslavia 1966-1978 (ed. Susovski, M.), Gallery of Contemporary Art, Zagreb, 1978, p. 19.

De Baere, B., Approaching Art through Ensembles en: L'Internationale. Post-War Avant-Gardes Between 1957 and 1986 (ed. Höller, C.), JRP Ringier, 2012.

Dragan, S., Video in novemedijska umetnost, en: Slika $v$ mediju in digitalna tvorba (ed. Žbona, T.), Koper 2014a, pp. 31-46.

Dragan, S., The meaning of video, en Video, et gaudeo. Celebrating the $15^{\text {th }}$ anniversary of ArtNetLab Society for Connecting Art and Science, Catálogo de exhibición, Ljubljana 2014b.

Dressler, I., Subversive Practices: Art under Conditions of Political Repression: 60s-80s / South America / Europe, en: Art under Conditions of Political Repression: 60s-80s / South America / Europe, Catálogo de la exhibición (eds. Christ, H. D., Dressler, I.), Stuttgart, Ostfildern 2010.

Kovič, B., The beginnings of Slovene video, en: VIDEODOKUMENT. Video art in Slovenia 1969-1998 (ed. Borčič, B.), Ljubljana, 1999, pp. 23-35.

Lešnik, B., Video and the 'alternative culture scene' of the 80's in Slovenia, en: VIDEODOKUMENT. Video art in Slovenia 1969-1998 (ed. Borčič, B.), Ljubljana, 1999, pp. 51-60.

Meigh-Andrews, C., A History of Video Art, New York, London 2014.

Montero Peña, M. V., Arte de los medios y transformaciones sociales en Chile durante la 'transición política' (1990-2014), Tesis, Universidad de Barcelona, 
http://arteymedios.org/images/pdf/Publicaciones/Arte-de-los-medios-ytransformaciones-sociales-en-Chile_Valentina-Montero.pdf [25. 6. 2017].

Peluffo Linari, G., Artes visuales, Colección Nuestro Tiempo, Libros del Bicentenario, Montevideo 2014.

Puchet, M., Octaedro, Los Otros y Axioma. Relecturas del Arte Conceptual en el Uruguay durante la dictadura (1973-1985), Montevideo 2014.

Preda, C., The artist as witness in dictatorial regimes in Eastern Europe and South America, en: ECPR General Conference Science Po, Bordeaux, 4-7 de setiembre de 2013, Panel: Art as political Witness, https://ecpr.eu/Filestore/PaperProposal/ d10d7531-814b-44d4-8b03-3f3494c43bb8.pdf [21. 6. 2017].

Preda, C., Art and Politics in Modern Dictatorships in the Southern Cone and Eastern Europe. A Preview of Theoretical Problems, en: New Europe College Ştefan Odobleja Program Yearbook 2014-2015 (ed. Vainovski-Mihai, I.), Bucarest 2015, pp. 55-82.

Sichel, B., Primera generación. Arte e imagen en movimiento, 1963-1986, Catálogo de la exhibición, Madrid 2006.

Taquini, G., Tiempos del video argentino, en: Historia Crítica del Video Argentino (comp. LaFerla, J.), Buenos Aires 2008, pp. 25-48.

Zajc, M., Video production in Slovenia prior to 1969, en: VIDEODOKUMENT. Video art in Slovenia 1969-1998 (ed. Borčič, B.), Ljubljana, 1999, pp. 91-110. 


\section{Francisco Tomsich}

\section{Enosmerno neskladje. Zaznamki o izvoru videoumetnosti v Urugvaju in Sloveniji}

Ključne besede: videoumetnost, Urugvaj, Slovenija, konceptualizem, diktatura, alternativna kultura

Pričujoči prispevek obravnava nekatere težavne vidike primerjalnih študij med vzhodnoevropskimi in južnoameriškimi državami skozi uvod v proučevanje izvora videoumetnosti v Urugvaju in Sloveniji. Avtor analizira nekatere problematike, povezane $\mathrm{z}$ vprašanjem izvora videoumetnosti na splošno, in predlaga tipološki model razvrščanja pionirskih del, da bi našel sredstva, ki bi omogočila primerjavo zelo različnih panoram Urugvaja in Slovenije na področju raziskovanja in arhiviranja zgodovinske videoumetnosti, ter nakazal glavne razlike med kontekstoma pojavitve in osrednje značilnosti začetne produkcije na tem področju v obeh državah. Neskladje med državama, ki pod vprašaj postavlja pojmovanje obeh kot podobnih si obrobnih območij hegemoničnih umetniških središč, je ponazorjeno skozi študijo del, ki veljajo za prva na področju videoumetnosti v Sloveniji (Belo mleko belih prsi, Srečo in Nuša Dragan, 1969) in Urugvaju (Voy por el camino, Grupo Teatro Danza de Montevideo, 1982). To neskladje kaže, kako težavna je lahko vzpostavitev plodovitih primerjav med političnimi režimi, v katerih se takšne prakse rodijo. Kljub vsemu pa prav ta težavnost na podlagi podobnih poskusov primerjav spodbuja premišljevanja, ki vodijo $\mathrm{k}$ razumevanju sodobnih fenomenov ter najbolj razširjenih tegob v kulturi in umetnosti tako v Urugvaju kot v Sloveniji. 


\section{Francisco Tomsich}

\section{Single-direction offset. Notes on the origins of video art in Uruguay and Slovenia}

Keywords: Video art, Uruguay, Slovenia, conceptualism, dictatorship, alternative culture

This article deals with some problems that we face when comparing recent art histories from Eastern Europe and South America. The focal case is the origins of video art in Uruguay and Slovenia. The first section poses the question of the origins of video art in general as one of the many issues that make it very difficult to produce narratives on the medium's history, an aspect which has great political and aesthetic consequences. We postulate a typological model of classification of pioneering works of video art in order to acquire some useful tools to compare the very dissimilar panoramas of Uruguay and Slovenia regarding video art historiography and archiving. The gap between the pioneering production of video art (understood as using magnetic tape) in Uruguay and Slovenia calls into question the common practice of referring to both countries as on similar margins of the hegemonic artistic centres. We analyse those works considered foundational of video art production in Slovenia (Belo mleko belih prsi, Srečo and Nuša Dragan, 1969) and Uruguay (I'm on the way, Grupo Teatro Danza de Montevideo, 1982), in order to outline the difficulty of establishing operative comparisons between the political and social contexts in which these practices emerged, a difficulty that nevertheless acts as a stimulus to produce new approaches to contemporary cultural and artistic phenomena, both in Uruguay and Slovenia. 